\title{
The Blues/Funk Futurism of Roger Troutman
}

\section{Scot Brown}

More than a decade after his tragic death, the sonic innovations of Roger Troutman - known simply as Roger and leader of the group called Zappcontinue to influence pop music. Contemporary artists such as Kanye, Akon, and T-Pain owe a tremendous debt to Roger's brand of electronic funk. Though reigning supreme during the $1980 \mathrm{~s}$, his sound built on the commingling of technology and futuristic representations in film and television decades earlier. Beyond television and movie screens, African American musical artists created accessible avenues for futuristic representation through musical art. Lyrics, concepts, costumes, and album cover art, from a range of musical styles, evoked futuristic imagery set in outer space or imaginary places to frame commentaries on love, human possibility, politics, and racial conflict. Musical illustrations of the future were often textured by new technologies of sound used in scores for postwar science fiction film and television. Tonal companions to the American Aquarian age were wrought with technological enthusiasm and anxieties - most notably expressed in numerous guitar effects (popularized by Jimi Hendrix) and the synthesizer, which, in keeping with its namesake, created analogues to traditional sounds and synthesized altogether new ones.

Roger Troutman is most known for expanding the range and melodic possibilities of the talk box or voice box - a device that allows an artist to fuse vocal patterns with the sound emitted by electronic instruments and mimic speech. After more than twenty years as a regional midwestern act, Roger and his broth- 
ers' group Zapp emerged with the 1980 single "More Bounce to the Ounce," which introduced audiences to his signature talk box style. Roger described his use of the device with imagery that associated it with science fiction film and television: "I consider the voice box ... like an African robot. . . . It says logical things that a computer says, but instead of saying them very drab and disgusting as a robot would say ... I can sound computerized and I can also sound real funky."'

Though precursors to this effect date back to the 1930s, the talk box emerged in popular music during the late 1960s, overlapping with the widespread use of synthesizers. Roger Troutman was in his early twenties when inspired by Stevie Wonder, who frequently used the talk box during live performances in the 1970s. Wonder's maturation as an adult artist was distinguished by the specialized branding of his musical genius - his blindness notwithstanding, Wonder could conduct an entire recording, playing all of the instruments and doing all of the vocals. Throughout the 1970s, the recording studio expanded its place as the terrain for individualized expressions of musical genius - a path followed by many other artists, including Patrice Rushen, Rick James, and Prince. Roger Troutman was practically groomed for this brand of virtuosity, mastering numerous instruments as a child prodigy - the guitar, piano, bass, and harmonica. Having grown up in Hamilton, Ohio, just in between Dayton and Cincinnati, he and his brothers - Lester, Larry, and Terry - formed a band initially known as Little Roger and the Vels, then later Roger and the Human Body, and then Zapp.

Troutman recalled that his band Roger and the Human Body independently released the single "Freedom" on their own Troutman Bros. label, and it was a regional hit in 1975. "It was number 1 in the Ohio area," he remarked. "We didn't have any national distribution because we just put the record out . . . [w]e paid for it ourselves." Many acts from Ohio and throughout the tristate area were able to ascend to regional stardom. The area was ripe with independent record labels and disc jockeys at stations like WDAO (Dayton) who frequently aired singles by local bands. Numerous artists who would never acquire deals with major record labels had scored local hits that were played on the radio and could be purchased at neighborhood record stores. The early, presynthesizer Roger sound had the steadiness of a James Brown-inspired groove with an unwavering natural electric bass line, choppy rhythm guitar licks and conga patterns. The only hint of the forthcoming electronic Roger and Zapp brand was a short guitar solo connected to a talk box, which sounded more like a distant effect than anything that could ever materialize as a principal instrumental voice.

"Freedom" has the gritty quality of a live recording from one of the innumerable performances of the band in the midwestern "Chitlin' Circuit." The live music scene out of which Roger and Zapp emerged underscores a period in which music forged connections between businesses, schools, families, and other black community institutions. As the Troutman brothers secured their big break with a record deal with Warner Bros.-after a brief and contentious stint 
with George Clinton's Uncle Jam Records - a new decade was initiating sweeping changes in popular music. By the mid-1980s, horns, bass guitars, congas, and timbales were displaced by the dominance of the synthesizer and drum machine. Only a relatively small number of funk groups successfully adapted: Roger and Zapp, Cameo, Midnight Star, Lakeside, The Dazz Band, Mtume, Klymaax, and a handful of others.

Roger's early interest in new sounds best prepared him for the coming musical age. Unlike his predecessors-Sun Ra, Parliament-Funkadelic, and Bootsy's Rubberband - Roger did not link his high-tech funk sound to a science fiction or surreal story line (such as the epic battle between Starchild and Sir Nose D'Void of Funk in the song "Flash Light"). Instead, Roger "played" with notions of linear "progress," conjoining futuristic sounds with stories about down-to-earth or time-honored lyrical themes - such as the need for commitment, love, money, and setting aside time to party and enjoy life in the midst of its constant challenges. In 1980, "More Bounce to the Ounce," the first single released from Zapp's eponymous debut LP, stood as a declaration of sonic progress - obviously, the fattened Minimoog Bass line offered much more bounce than the standard four-string bass guitar. However, when interviewed two years later, Roger offered another dimension to the lyrics: "More Bounce ... deals with checks that bounce and I mean what else do you do when your checks bounce but just forget them and have a good time until you can make them good." 3

Troutman used instrumentation to tamper with ways of thinking about the essence of time itself, employing the talk box and synthesizer alongside instruments associated with older music genres - blues, jazz, and doo-wop. Roger's 1981 solo album The Many Facets of Roger is a musical place where jazz and blues guitar licks meet up with synthesizers to create nothing short of a masterpiece. A literal fusion of the two is best conveyed in the song "Max Axxe," Roger's ode to and brilliant display of a new instrument, the guitar synthesizer. He also played the harmonica as the lead instrument on the song "Do Wa Diddy" and used the talk box as the voice for doo-wop-styled vocal arrangements. On the same LP, Roger continued to obliterate future/past distinctions with his funky robotic voice singing a remake of the Motown classic "I Heard It through the Grapevine." Additionally, Roger's meditations on the processes by which digital technologies were transforming social relations had a prophetic quality. When Zapp's single "Computer Love" was released in 1985, the Internet did not exist in mass communications, and the idea of real-time face-to-face encounters on a visual monitor were more likely seen on reruns of The Jetsons than anything approximating reality. "Computer Love" contemplated the impact of new technologies on the age-old search for love.

Roger once described his music as the "blues for the eighties." "This characterization would bespeak not only his guitar chops but also concern about the widespread loss of jobs in urban areas throughout the United States. Anxieties about these hard times appear in a number of Troutman's songs: "So Ruff, So 
Tuff” (1981), "Playin' Kinda Ruff" (1982), "We Need the Buck" (1983), and "Jesse Jackson" (1989). Roger was not satisfied, however, with music as a lone response to these problems. The Troutman family made Dayton, Ohio, the locale of its residence and entrepreneurial activities. Using contemporary lingo, Troutman Enterprises, founded in 1980, would be called a "social enterprise"a company that situates solutions to social problems as part of its primary mission. It was made up of numerous businesses - recording studio, construction company, and limousine service - committed to training and employing displaced African American workers and youth in Dayton.

In 1983, Roger described the Troutman construction business in terms simulating the reciprocal pleasures exchanged between musicians, audiences and listeners in performance and recording: stating that

I noticed, when we would do live shows that people would feel good, but they would only feel good until that night. I mean I couldn't prolong that feeling. So, "then we" started making records and I noticed that people could pick the record up and prolong the feeling a little longer and then we started doing things with our construction company, getting people into different neighborhoods and refurbishing homes and turning debilitated houses into beautiful [ones] and then reinstating those tenants back into that property and then to see the look on their face and see how happy they are. It's the same sensation, but the difference between the records and the shows and doing something for somebody's home is that every time, they are always in their home and the feeling is just almost a lifetime. ${ }^{5}$

Though Roger was a part of a community that had once generated its own local music celebrities, he was troubled by the limits in opportunity structures for black youth. "I hate to see," Roger lamented, "black kids wanting to play ball or wanting to be musicians. There is nothing wrong with it," he continued, "but we need doctors, we need lawyers, we need builders, we need carpenters." The objectives of Troutman Enterprises were eventually overtaken by the economic difficulties of the era as the company folded during the early 1990s. The overlapping sound research and social activism of Roger and the Troutman family, nevertheless, is a powerful metaphor for the challenges presented for the black experience in postindustrial America.

The downsizing of big bands in black music mirrored the economic calamity of deindustrialization that downsized jobs and wages of workers in cities like Dayton across the country. Factors beyond the turn of events in Dayton would, nevertheless, keep Roger's brand of funk - and funk music at largevery much alive in American popular music. The funk of the 1970s and 1980s was reintroduced to latter-day audiences through the frequent use of sampling 
in hip hop, especially during the 1990s and coming new millennium. Young producers found the bass lines and talk box of Roger an irresistible funk landscape-Zapp's (1980) "More Bounce to the Ounce," and "Dance Floor" were sampled in EPMD's "You Gots to Chill" (1988) and also by Notorious B.I.G. in "Going Back to Cali" (1997) and "Be Alright" (1980) and in 2Pac's "Keep Ya Head Up" (1998), among many others. ${ }^{7}$ Beyond sampling, Roger's collaborations with younger artists helped to bridge the generational divide between instrumentally trained musicians of the 1970s and the DJ and turntablist-inspired artists of the hip-hop generation, working directly with 2Pac, Dr. Dre, Snoop Dogg, H-Town, DJ Quik, and many others. Undoubtedly, Roger Troutman's funk legacy will continue to alter the future of music.

\section{Notes}

1. Zapp (Roger Troutman), Karen Shearer Papers, Archives of African American Music and Culture, Indiana University, August 19, 1982, 2.

2. Ibid., 7.

3. Ibid., 2.

4. Rickey Vincent, Funk: The Music, the People and the Rhythm of the One (New York: St. Martin's Press, 1996), 280.

5. Zapp (Roger Troutman), Karen Shearer Papers, Archives of African American Music and Culture, Indiana University, August 4, 1983, 13.

6. Zapp (Roger Troutman), Karen Shearer Papers, Archives of African American Music and Culture, Indiana University, November 15, 1983, 12.

7. Thompson, Funk. 
